\title{
Influence of dietary arginine on the anabolic effects of androgens
}

\author{
A Cremades ${ }^{1}$, C Ruzafa, F Monserrat, A J López-Contreras and \\ R Peñafiel \\ ${ }^{1}$ Department of Biochemistry and Molecular Biology and Department of Pharmacology, Faculty of Medicine, University of Murcia, Campus de Espinardo, \\ 30100 Murcia, Spain \\ (Requests for offprints should be addressed to R Peñafiel; Email address: rapegar@um.es)
}

\begin{abstract}
Feeding mice an arginine-deficient diet decreased plasma concentrations of arginine, citrulline and ornithine in the females and arginine in the males, abolishing the sexual dimorphic pattern of these amino acids found in mice fed the standard diet. In addition, the restriction of dietary arginine produced a marked decrease in body and renal weights as well as in the activity of renal ornithine decarboxylase, decreases that were gender dependent since they were observed exclusively in males. The fact that these changes were not associated with the decrease in the circulating levels of testosterone and that the dietary arginine restriction prevented the body weight gain induced by testosterone treatment of female mice fed the standard diet indicates that dietary arginine is required for
\end{abstract}

the anabolic action of androgens. Moreover, under certain conditions that could compromise the renal synthesis of arginine, as in the compensatory renal hypertrophy that follows unilateral nephrectomy, the myotrophic effect of testosterone was transiently impaired. The results also revealed that arginine deficiency produced an opposite effect in the expression of IGF-I and IGF-binding protein 1 in the liver and kidney. Taken together, our results indicate that dietary arginine may be relevant to the anabolic action of testosterone, and suggest that this effect may be mediated by changes in the insulin-like growth factor system.

Journal of Endocrinology (2004) 183, 343-351

\section{Introduction}

Androgens are responsible for the induction of the male phenotype and for the regulation of the growth and differentiation of several extragenital tissues (Bardin \& Catterall 1981). Most androgen actions are mediated through the androgen receptor (AR) belonging to the superfamily of nuclear receptors. Upon binding to cisacting DNA elements, androgen-AR complexes regulate the transcription of androgen-responsive genes (Brinkman et al. 1999, Verhoeven \& Swinnen 1999, Kadi et al. 2000, Sheffield-Moore 2000). Many lines of evidence indicate that different hormones and growth factors, such as growth hormone (Jansson et al. 1985, Veldhuis \& Iranmanesh 1996, Niermann \& Watson 1999), catecholamines (Hannan et al. 1991) and insulin-like growth factors (Hobbs et al. 1993, Niermann \& Watson 1999, GayanRamirez et al. 2000), may modulate androgen action, probably by affecting the phosphorylation of AR or by interacting with different coactivators or corepressors (Urban et al. 1995, Verhoeven \& Swinnen 1999, Sheffield-Moore 2000, Kuhn 2002).

Apart from the role of hormonal and genetic factors in the control of growth, nutritional signals, and among these the amino acids, also play an important role in the regulation of genes involved in the control of growth (Fafournoux et al. 2000). L-Arginine is an important amino acid that participates in multiple biochemical processes in mammals. In addition to its implication in the urea cycle and protein synthesis, it serves as a precursor for the synthesis of amino acids, nitric oxide, polyamines, creatine, agmatine and other guanidino compounds (Barbul 1986, Morris 1992, Reyes et al. 1994, Wu \& Morris 1998, $\mathrm{Wu} \&$ Meininger 2002). In most mammalian species, arginine is not considered an essential amino acid for healthy adults, since it can be synthesized in the tubular cells of the kidney from the citrulline generated in the small intestine (Rose et al. 1954, Visek 1986, Dhanakoti et al. 1990). However, arginine may be considered a conditionally essential amino acid for adult animals under certain stressful conditions, and for young and growing animals, when the endogenous synthesis is inadequate to accomplish arginine requirements (Visek 1986, Reyes et al. 1994, Cynober et al. 1995). In addition, it has been reported that supplemental dietary arginine may have beneficial effects since it enhances wound healing and angiogenesis, improves protein anabolism, stimulates the immune functions and ameliorates cardiovascular disorders (Adjei et al. 1995, Cui et al. 1999, Shi et al. 2000, Boger \& Bode-Boger 2001). 
Homeostasis of L-arginine in plasma is regulated by dietary arginine intake, protein turnover, transport, arginine synthesis and catabolism (Barbul 1986, Morris 2002). The relative importance of these processes may be dependent on different factors such as age, animal species or dietary salt intake (Castillo et al. 1994, Kitiyakara et al. 2001). Thus, while endogenous synthesis of arginine plays an important role in regulating arginine homeostasis in neonatal and growing pigs (Wu \& Knabe 1995), dietary arginine intake appears to be the main regulator of arginine levels in adult humans (Castillo et al. 1994). In rodents, it has been reported that feeding adult animals an arginine-deficient diet decreased arginine concentration in plasma (Gross et al. 1991). In a recent study, we found that there is a marked gender dimorphism in the levels of arginine in plasma, kidney and skeletal muscle, female mice having higher levels than males (Ruzafa et al. 2003). Moreover, the restriction of dietary arginine produced a marked decrease of arginine in plasma and tissues that almost abolished the sexual dimorphism found in the levels of this amino acid. This dietary restriction also affected the activities of enzymes related to the metabolism of arginine and ornithine that are regulated by sex hormones, suggesting the existence of some interaction between dietary arginine and hormone action (Ruzafa et al. 2003).

In the present study, we have investigated the influence of dietary arginine in the metabolic action of testosterone in mice, a species in which testosterone is the major determinant of the gender dimorphism found in extragenital tissues (Koening et al. 1980, Bardin \& Catterall 1981). We have studied the influence of dietary arginine in renal size, renal ornithine decarboxylase activity and body weight gain, since these parameters are clear indicators of the anabolic action of testosterone in extragenital tissues (Berger \& Watson 1989). Moreover, we have also studied the influence of conditions in which renal arginine synthesis may be compromised, as in the case of recovery after unilateral nephrectomy, in the action of androgens.

\section{Materials and Methods}

\section{Animals and treatments}

Male and female Swiss CD1 mice (Harlan Interfauna Ibérica, Barcelona, Spain) weighing 35-40 (males) and 26-30 g (females) were bred in our animal facilities. They were housed at $22 \pm 1{ }^{\circ} \mathrm{C}$ ambient temperature and 50\% relative humidity under a 12-h light-dark cycle (lights on at $0800 \mathrm{~h}$ ) in stainless-steel cages. They were divided into different groups that received commercial rodent solid diets and water ad libitum. The standard chow (A04; Panlab, Barcelona, Spain) contained $17 \%$ proteins, $3 \%$ fat, $59 \%$ carbohydrate, $12 \%$ moisture, $4 \%$ fiber, $1 \%$ vitamins and $4 \%$ minerals, with a caloric content of about $2900 \mathrm{kcal} / \mathrm{kg}$. The L-arginine, L-lysine and L-methionine contents of the diet were $0.98 \%, 0.85 \%$ and $0.31 \%$ respectively. The arginine-deficient diet (ICN Biomedicals, Aurora, OH, USA) contained 46.4\% sucrose, $23 \cdot 1 \%$ cornstarch, $10 \%$ corn oil, $0.5 \%$ AIN 76 vitamin mix, $5 \%$ AIN 76 mineral mix, $0 \cdot 2 \%$ choline bitartrate, $0 \cdot 26 \%$ L-histidine free base, $0.53 \%$ L-isoleucine, $0.71 \%$ L-leucine, $1 \cdot 16 \%$ L-lysine $\mathrm{HCl}, \quad 0.53 \%$ L-methionine, $0.75 \%$ L-phenylalanine, $0.53 \%$ L-threonine, $0.53 \%$ L-valine, $2 \cdot 25 \%$ L-glutamic acid, $0.75 \%$ glycine, $0.11 \%$ L-tryptophan, $1 \cdot 26 \%$ L-alanine, $0.66 \%$ L-aspartic acid, $0.81 \%$ L-proline, $0.75 \%$ L-cysteine free base, $1.26 \%$ L-serine, $0.81 \%$ L-tyrosine and $1.01 \% \mathrm{~L}$-asparagine anhydrous. For arginine supplementation, animals were fed the arginine-deficient diet and L-arginine (in the hydrochloride form) in the drinking water. Arginine solutions were changed daily. The $\mathrm{pH}$ of the aqueous solutions with 0,1 and $5 \%$ arginine were $7 \cdot 2,7 \cdot 1$ and $6 \cdot 8$ respectively.

Nephrectomy was performed under ether anesthesia in adult female mice. The right kidney was removed and weighed immediately after surgery. Mice were killed 2-4 weeks after nephrectomy, and the remaining kidney was removed and weighed. Adult female mice were treated with testosterone propionate $(100 \mathrm{mg} / \mathrm{kg})$ and killed after 2 weeks of treatment. Testosterone propionate, purchased from Sigma, was dissolved in olive oil and injected subcutaneously every other day. Growth hormone $(10 \mu \mathrm{g})$ was injected subcutaneously every $12 \mathrm{~h}$ for 20 days.

Animals were killed by cervical dislocation under ether anesthesia, and tissues were quickly removed, weighed and processed. Procedures involving animals and their care were conducted in conformity with institutional guidelines that comply with national (RD 223/1988) and international laws and policies (EEC Council Directive 86/009; NIH Guide for the Care and Use of Laboratory Animals, NIH publication no. 85-23 1985).

\section{Amino acid analysis}

Blood was collected by cardiac puncture under light ether anesthesia. After centrifugation, plasma was collected and treated with 5\% trichloroacetic acid $(1: 5 \mathrm{w} / \mathrm{v})$. After centrifugation at $10000 \mathrm{~g}$ for $10 \mathrm{~min}$, the supernatants were analyzed. Amino acids were isolated by ion-exchange chromatography with an amino-acid autoanalyzer (Chromaspeck; Rank Hilger Analytical, Westwood, Kent, UK) and detected by fluorometry after reaction with o-phthaldialdehyde (Sigma). Norleucine was used as internal standard. The system was calibrated with $0.01 \mathrm{mM}$ amino-acid standard solution, including physiological acidic, neutral and basic amino acids (Sigma). Amino-acid concentrations in plasma were calculated and expressed as $\mathrm{mM}$.

\section{Enzymatic measurements}

For enzyme determination, kidneys were homogenized with the aid of a Polytron homogenizer in buffer 
Table 1 Effect of dietary arginine restriction on body and renal weights. Animals were fed an arginine-deficient diet (AD) for 20 days. Results are the means \pm S.D. Number of animals per group: 12. Relative kidney weight represents the ratio between the weight of a pair of kidneys (mg) and the body weight (g)

\section{Body weight $(\mathrm{g})$}

Initial Final

\section{Treatment}

Control male

AD male

Control female

AD female

$\begin{array}{ll}40 \cdot 7 \pm 2 \cdot 8 & 41 \cdot 2 \pm 2 \cdot 2 \\ 42 \cdot 0 \pm 1 \cdot 7 & 38 \cdot 7 \pm 3 \cdot 1^{\mathrm{a}} \\ 29 \cdot 4 \pm 2 \cdot 1 & 29 \cdot 5 \pm 2 \cdot 0 \\ 27 \cdot 5 \pm 1 \cdot 2 & 27 \cdot 6 \pm 0 \cdot 9\end{array}$

Body weight gain $(\mathrm{g})$

$$
\begin{aligned}
0 \cdot 36 & \pm 0 \cdot 50 \\
-3 \cdot 2 & \pm 0 \cdot 7^{b} \\
0 \cdot 1 & \pm 0 \cdot 1 \\
0 \cdot 8 & \pm 0 \cdot 6
\end{aligned}
$$

Kidney weight (mg)

$332 \pm 35$
$260 \pm 43^{b}$
$170 \pm 23$
$159 \pm 10$

Relative kidney weight $(\mathrm{mg} / \mathrm{g})$

\author{
$16 \cdot 3 \pm 1 \cdot 7$ \\ $13 \cdot 2 \pm 1 \cdot 6^{b}$ \\ $10 \cdot 9 \pm 2 \cdot 3$
}

$11 \cdot 8 \pm 0$

${ }^{a} P<0 \cdot 01$ vs initial weight.

${ }^{\mathrm{b}} P<0 \cdot 001$ vs control male.

containing $25 \mathrm{mM}$ Tris ( $\mathrm{pH} 7 \cdot 2$ ), $2 \mathrm{mM}$ dithiothreitol, $0 \cdot 1 \mathrm{mM}$ pyridoxal phosphate, $0 \cdot 1 \mathrm{mM}$ EDTA and $0.25 \mathrm{M}$ sucrose. The extract was centrifuged at $20000 \mathrm{~g}$ for $20 \mathrm{~min}$, and ornithine decarboxylase (ODC) activity was determined in the supernatant. ODC activity was determined basically as described by Russell and Snyder (1968) by measuring ${ }^{14} \mathrm{CO}_{2}$ release from $\mathrm{L}-\left[1-{ }^{14} \mathrm{C}\right]$ ornithine. The incubation mixture contained $20 \mathrm{mM}$ Tris $(\mathrm{pH} 7 \cdot 2)$, $0.1 \mathrm{mM}$ pyridoxal phosphate, $0.1 \mathrm{mM}$ EDTA, $2 \mathrm{mM}$ dithiothreitol and $0.4 \mathrm{mM} \mathrm{L}-\left[1-{ }^{14} \mathrm{C}\right]$ ornithine (New England Nuclear, Boston, MA, USA) (specific activity $2.6 \mathrm{Ci} / \mathrm{M}$ ) in a total volume of $62.5 \mu \mathrm{l}$. The samples were incubated at $37^{\circ} \mathrm{C}$ for $30 \mathrm{~min}$, and the reaction was stopped by adding $0.5 \mathrm{ml}$ of $2 \mathrm{M}$ citric acid. Activity was expressed as $\mu \mathrm{mol} \mathrm{CO}_{2}$ produced per hour and per gram of wet weight.

\section{Testosterone analysis}

Plasma was obtained by centrifugation at $4{ }^{\circ} \mathrm{C}$ and was kept frozen at $-70{ }^{\circ} \mathrm{C}$ until analysis. Testosterone was determined by ELISA, using Enzymun-test kits supplied by Boehringer Mannheim Immunodiagnostics (Mannheim, Germany).

\section{RT-PCRs}

Total RNA was extracted from tissues with the RNAqueous-Midi Kit (Ambion, Austin, TX, USA) and purified according to the manufacturer's specifications. Total RNA was reverse transcribed, using oligo $(\mathrm{dT})_{18}$ as primer and (M-MLV) reverse transcriptase (Ambion). Products were amplified by means of Taq polymerase (Sigma), using specific primers pairs within the linear range for each gene product. Amplified products were resolved by electrophoresis in 2\% agarose gels containing $40 \mathrm{mM}$ Tris/acetate and $1 \mathrm{mM}$ EDTA $(\mathrm{pH} 8.0)$ in a horizontal slab gel apparatus using 1 TAE buffer. The gel was stained with ethidium bromide $(0 \cdot 2 \mu \mathrm{g} / \mathrm{ml}$ for $15 \mathrm{~min}$ ), followed by destaining in water, photographed by
UV transilumination by a Gel Doc system camera (Bio$\mathrm{Rad}$ ), and the bands were quantified with Multi-Analyst software. Primers (from Sigma) were as follows:

- mouse IGF1 (accession no. AF440694), 8-380: forward 5'-CTTCACATCCTCTCTACCT, reverse 5'ATTCTGTAGGTCTTGTTTCC

- mouse IGF-binding protein (BP) 1 (accession no. NM_008341), 581-950: forward 5'-AAAGGCTGCTGT GGTCTCCG, reverse 5'-TCCACTCCATGGGTAGA CAC

- mouse IGF1 receptor (R) (accession no. NM_010513), 3221-3820: forward 5'-AGCCCACCCT GGTCAT catg, reverse 5'-GCTCCATCTCATCCTTG ATG.

\section{Statistical analysis}

Results are given as means \pm S.D. Statistical comparisons were calculated by ANOVA followed by the post-hoc Newman-Keuls multiple range test. The results were considered statistically significant when $P$ values were $<0 \cdot 05$.

\section{Results}

Feeding mice an arginine-deficient diet for 20 days produced a marked decrease in body and renal weights in the male mice, but the same treatment did not affect these parameters in the female mice (Table 1). This decrease in body weight was mainly associated with the loss of muscle mass, as was evident by comparing the size and weights of the lower legs (Fig. 1). Arginine deficiency also produced a significant decrease of arginine in the plasma of both sexes, while its product ornithine and its precursor citrulline were decreased significantly in the females (Table 2). It must also be noted that the concentrations of the three amino acids studied were higher in control females than in males, confirming previous findings of a sexual dimorphism of arginine in CD1 mice (Ruzafa et al. 2003). 


\begin{tabular}{lc}
\hline \multicolumn{1}{c}{ Treatment } & Weight (mg) \\
\hline Control (4) & $1813 \pm 163$ \\
Arginine-deficient (4) & $1445 \pm 187^{\mathrm{a}}$ \\
\hline
\end{tabular}
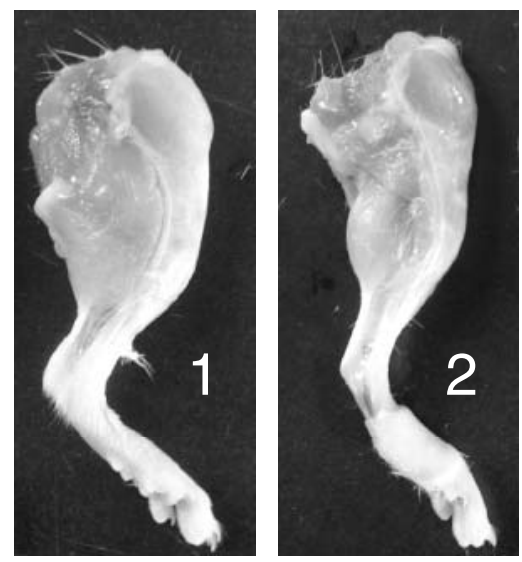

Figure 1 Influence of dietary arginine in lower leg weight and muscle mass of male mice. Lower legs from male mice fed an arginine-deficient diet for 20 days were dissected and compared with those from animals of the same weight fed the standard diet. The weights are the means \pm S.D. from four animals. (1) Control; (2) arginine-deficient. ${ }^{a} P<0 \cdot 01$.
Moreover, the supplementation of arginine-deficient male mice with $1 \%$ arginine in the drinking water for 10 days reversed the changes produced by arginine deficiency, while the daily administration of growth hormone to arginine-deficient male mice during the period of deficiency did not prevent the fall in body and renal weights (data not shown). There were no significant differences in the amount of food consumed by the animals fed the $0 \%, 1 \%$ and $5 \%$ arginine diets $(5.4 \pm 1.3 \mathrm{~g}$ /day for male mice and $4 \cdot 1 \pm 1 \cdot 1 \mathrm{~g} /$ day for female mice).

In order to test whether the decrease in kidney and body weights observed in the male mice under dietary arginine-restriction could be related to the diminution of androgens, plasma testosterone levels were measured. No significant variations between control mice $(7 \cdot 1 \pm 2 \cdot 4 \mathrm{ng} /$ $\mathrm{ml})$ and arginine-deficient mice $(6 \cdot 4 \pm 2 \cdot 0 \mathrm{ng} / \mathrm{ml})$ were observed.

The influence of arginine deficiency on the anabolic action of exogenous testosterone was studied by comparing the effect of administration of testosterone propionate on body and kidney weights of female mice fed standard chow and arginine-deficient diet. Table 3 shows that, in animals fed standard chow, testosterone propionate given subcutaneously for 15 days elicited a significant increase in both body and renal weights $(P<0 \cdot 001)$. However, in

Table 2 Influence of dietary arginine restriction on plasma arginine, ornithine and citrulline levels. Animals were fed an arginine-deficient diet (AD) for 20 days. Results are the means \pm s.D. Number of animals per group: $4-6$

\begin{tabular}{|c|c|c|c|c|}
\hline & \multicolumn{2}{|l|}{ Male } & \multicolumn{2}{|l|}{ Female } \\
\hline & Control & $A D$ & Control & $A D$ \\
\hline \multicolumn{5}{|c|}{ Amino acid (mM) } \\
\hline Arginine & $0 \cdot 108 \pm 0 \cdot 014$ & $0.045 \pm 0.003^{a}$ & $0 \cdot 152 \pm 0 \cdot 015^{c}$ & $0.043 \pm 0.005^{a}$ \\
\hline Ornithine & $0.081 \pm 0.024$ & $0.060 \pm 0.016$ & $0 \cdot 116 \pm 0.034^{c}$ & $0.058 \pm 0.006^{b}$ \\
\hline Citrulline & $0.064 \pm 0.016$ & $0.055 \pm 0.012$ & $0 \cdot 123 \pm 0 \cdot 015^{c}$ & $0.091 \pm 0.009^{b}$ \\
\hline
\end{tabular}

Table 3 Influence of dietary arginine on the effect of exogenous testosterone on body and renal weights. Mice fed standard, arginine-deficient (AD) or arginine-deficient diet supplemented with $1 \%$ arginine or citrulline in drinking water were treated with testosterone propionate $(100 \mathrm{mg} / \mathrm{kg}$, every $48 \mathrm{~h})$ for 20 days. Results are the means \pm S.D. of six animals per group.

Body weight $(\mathrm{g})$

\begin{tabular}{|c|c|c|c|c|}
\hline Initial & Final & Body weight gain ( $g$ ) & Kidney weight (mg) & Relative kidney weight $(\mathrm{mg} / \mathrm{g})$ \\
\hline $29 \cdot 7 \pm 1 \cdot 6$ & $32 \cdot 9 \pm 1 \cdot 5$ & $3 \cdot 2 \pm 1 \cdot 2^{\mathrm{a}}$ & $265 \pm 15$ & $16 \cdot 0 \pm 1 \cdot 7$ \\
\hline $28 \cdot 2 \pm 1 \cdot 3$ & $28 \cdot 5 \pm 1 \cdot 6$ & $0 \cdot 3 \pm 0 \cdot 7$ & $233 \pm 16$ & $16 \cdot 3 \pm 1 \cdot 7$ \\
\hline $29 \cdot 7 \pm 1 \cdot 6$ & $33 \cdot 4 \pm 1 \cdot 6$ & $3 \cdot 4 \pm 1 \cdot 1^{\mathrm{a}}$ & $316 \pm 24$ & $18 \cdot 7 \pm 1 \cdot 1$ \\
\hline $29 \cdot 8 \pm 0 \cdot 8$ & $32 \cdot 7 \pm 1 \cdot 3$ & $2 \cdot 9 \pm 1 \cdot 0^{\mathrm{a}}$ & $314 \pm 33$ & $18 \cdot 7 \pm 2 \cdot 1$ \\
\hline $36 \cdot 4 \pm 2 \cdot 4$ & $40 \cdot 6 \pm 1 \cdot 2$ & $4 \cdot 1 \pm 0 \cdot 8^{b}$ & $485 \pm 80$ & $23 \cdot 9 \pm 2 \cdot 4^{b}$ \\
\hline $38 \cdot 5 \pm 3 \cdot 0$ & $39 \cdot 2 \pm 3 \cdot 5$ & $0 \cdot 7 \pm 0 \cdot 6$ & $362 \pm 84$ & $17 \cdot 7 \pm 2 \cdot 1$ \\
\hline
\end{tabular}

Dietary treatment Standard $(\mathrm{F})$

$\mathrm{AD}(\mathrm{F})$

$A D+1 \% \operatorname{Arg}(F)$

$\mathrm{AD}+1 \% \operatorname{Citr}(\mathrm{F})$

$\mathrm{AD}+1 \% \operatorname{Arg}(\mathrm{M})$

$\mathrm{AD}(\mathrm{M})$

F: female; M: male. Number of animals per group: six. Relative kidney weight represents the ratio between the weight of a pair of kindeys (mg) and the body weight (g).

${ }^{\mathrm{a}} \mathrm{P}<0.001$ vs $\mathrm{AD}(\mathrm{F})$

b $P<0.001$ vs AD (M). www.endocrinology-journals.org 


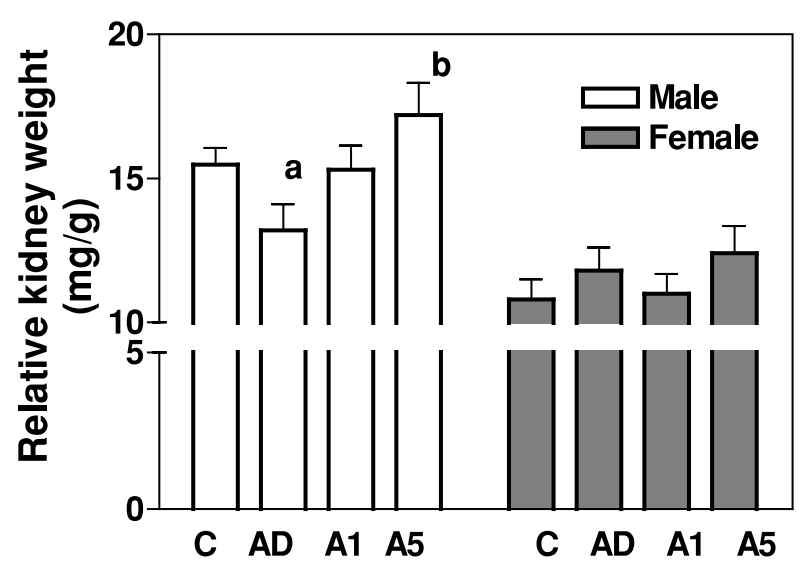

Figure 2 Influence of dietary arginine on relative renal size. Male and female mice were fed standard diet (C), arginine-deficient diet (AD) or arginine-deficient diet supplemented with $1 \%$ or $5 \%$ arginine in drinking water (A1 and A5 respectively) for 20 days. Results are the means \pm S.D. from 4-6 animals per group. Relative kidney weight represents the ratio between the weight of a pair of kidneys (in mg) and the body weight (g). (a) $P<0 \cdot 01$ vs control; (b) $P<0.01$ vs control and $P<0.001$ vs AD.

mice fed the arginine-deficient diet, the hormone did not affect body weight, although it increased renal mass, as shown in Table 3, which also shows that the concurrent administration of testosterone propionate and $1 \%$ arginine or $1 \%$ citrulline to arginine-deficient mice produced the same anabolic effects as those obtained when testosterone was given to mice fed standard chow.

Figure 2 shows the influence of arginine concentration in the diet on relative kidney weight. It can be seen that in male mice there is a direct relationship between the amount of dietary arginine and the renal mass. However, in female mice, the variation of dietary arginine concentration did not significantly affect renal weight. Arginine deprivation also decreased renal ODC activity in the male mouse as well as the induction elicited by exogenous testosterone in the kidney of the female mouse, as shown by Fig. 3, which also shows that arginine supplementation (up to 5\%) increased renal ODC activity in the male, while in the female kidney it did not significantly affect the action of testosterone propionate on this enzyme.

Next, we examined the influence of arginine restriction on body weight and renal compensatory hypertrophy induced by unilateral nephrectomy in female mice. Table 4 shows that the increases in the relative renal mass of the remaining kidney after 15 days of nephrectomy in animals fed $1 \%$ and $0 \%$ arginine were $27 \%$ and $19 \%$ respectively. The administration of testosterone propionate immediately after nephrectomy produced a higher increase in renal mass in both groups than in nontreated animals, reaching values of $76 \%$ and $69 \%$ respectively, but it did not affect body weight even in mice fed the standard diet, in contrast to sham operated mice, in which testosterone treatment, for an identical period of time, elicited a considerable increase in body weight. Table 4 also shows that the

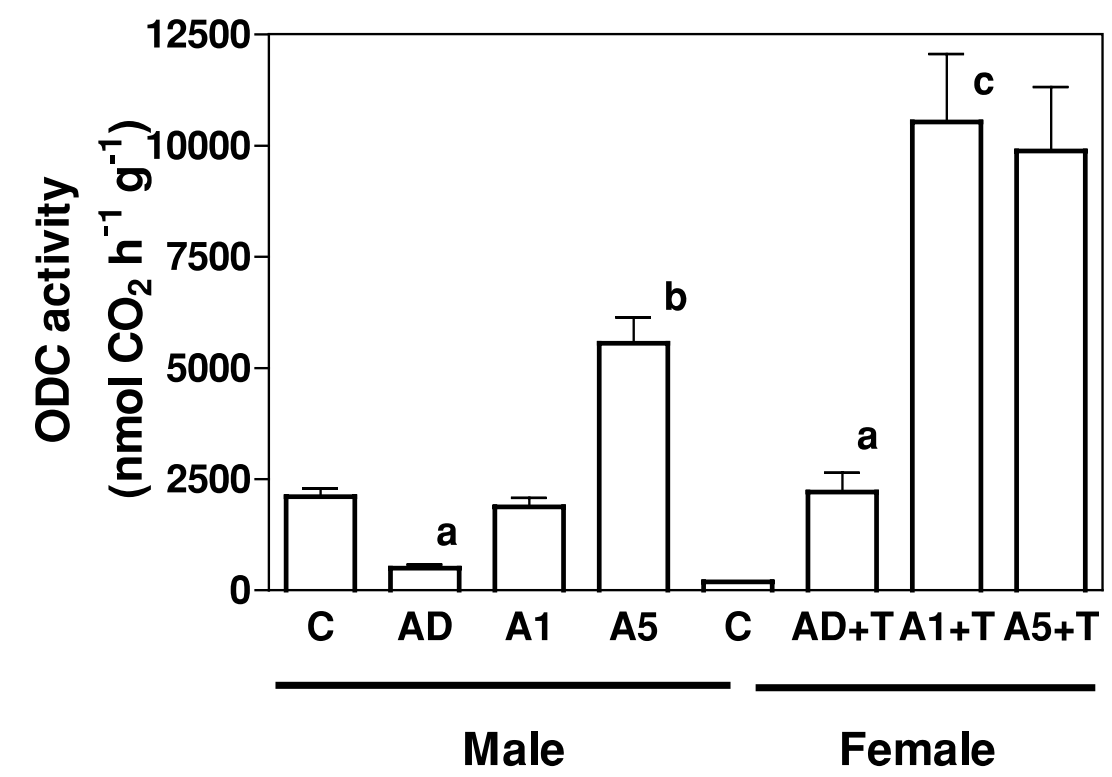

Figure 3 Renal ornithine decarboxylase (ODC) activity of mice under different dietary conditions. Male mice were fed standard diet (C), arginine-deficient diet (AD) or arginine-deficient diet supplemented with $1 \%$ or $5 \%$ arginine in the drinking water (A1 and $\mathrm{A} 5$ respectively) for 20 days, in the absence or presence of testosterone (T). Results are the means \pm S.D. from $4-6$ animals per group. a) and b) $P<0.001$ vs control; c) $P<0.001$ vs $A D+T$. 
Table 4 Influence of nephrectomy on the effect of testosterone in body and renal weights in the female mice. Nephrectomized female mice (NE) were fed standard or arginine-deficient diet (AD) for 15 or 30 days and treated with testosterone propionate $(100 \mathrm{mg} / \mathrm{kg}$, every $48 \mathrm{~h})$ for 15 days, starting immediately after nephrectomy (NE+T) 15 , or 15 days after nephrectomy (NE30+T15). Results are the means \pm S.D. of six animals per group

Relative kidney weight $(\mathrm{mg} / \mathrm{g})$

\begin{tabular}{|c|c|c|c|c|}
\hline & Diet & 1st kidney & 2nd kidney & Body weight gain (g) \\
\hline \multicolumn{5}{|l|}{ Treatment } \\
\hline NE15 & Standard & $11 \cdot 3 \pm 1 \cdot 1$ & $14 \cdot 4 \pm 2 \cdot 2^{a}$ & $0 \cdot 2 \pm 0 \cdot 6$ \\
\hline NE15 & $\mathrm{AD}$ & $11 \cdot 2 \pm 1 \cdot 3$ & $13 \cdot 3 \pm 1 \cdot 6^{a}$ & $-1 \cdot 1 \pm 0 \cdot 8$ \\
\hline$(\mathrm{NE}+\mathrm{T}) 15$ & Standard & $11 \cdot 7 \pm 0 \cdot 8$ & $20 \cdot 5 \pm 1 \cdot 5^{a}$ & $0 \cdot 1 \pm 0 \cdot 1^{b}$ \\
\hline$(\mathrm{NE}+\mathrm{T}) 15$ & AD & $11 \cdot 6 \pm 0.7$ & $19 \cdot 5 \pm 1 \cdot 6^{a}$ & $-1 \cdot 0 \pm 0 \cdot 5$ \\
\hline $\mathrm{NE} 30+\mathrm{T} 15$ & Standard & $12 \cdot 0 \pm 0 \cdot 6$ & $22 \cdot 5 \pm 2 \cdot 0^{a}$ & $3 \cdot 8 \pm 0 \cdot 5^{c}$ \\
\hline $\mathrm{NE} 30+\mathrm{T} 15$ & $\mathrm{AD}$ & $11 \cdot 9 \pm 0.8$ & $24 \cdot 3 \pm 1 \cdot 3^{a}$ & $0 \cdot 7 \pm 1 \cdot 0$ \\
\hline Sham +T15 & Standard & - & $16 \cdot 4 \pm 1 \cdot 8$ & $3 \cdot 3 \pm 0 \cdot 5$ \\
\hline
\end{tabular}

administration of testosterone 15 days after nephrectomy increased body weight as much as in sham operated animals only when arginine was present in the diet.

The levels of mRNA of IGF1, IGFBP1 and IGF1R in tissues from control and arginine-deficient male mice were estimated by semiquantitative RT-PCR analysis and compared with those of the constitutive protein $\beta$-actin. Figure 4 shows a higher expression of IGF1R in kidney than in liver, while the opposite was true for IGF1. Arginine deficiency produced a small decrease in IGF1 expression in the kidney and a significant increase of

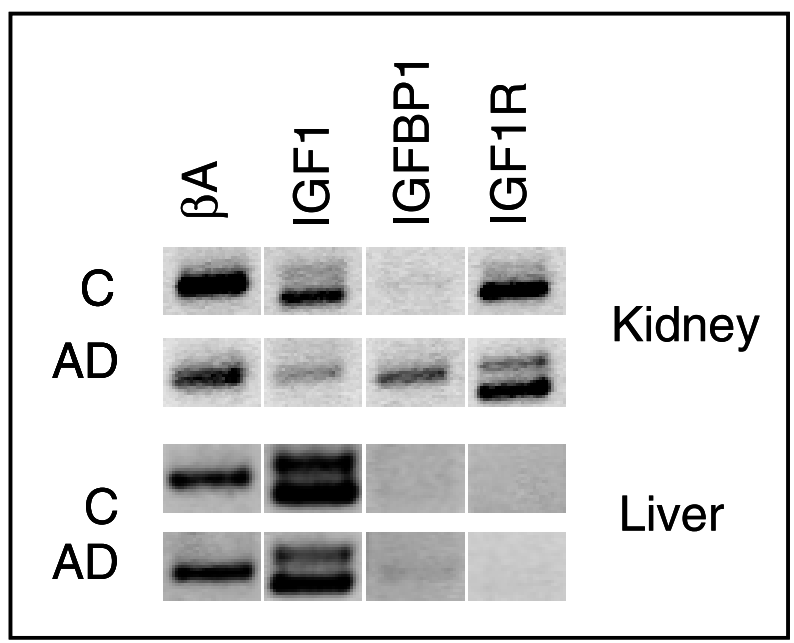

Figure 4 mRNA levels of IGF1, IGFBP1 and IGF1R in liver and kidney of control and arginine-deficient mice. Male mice were fed standard diet or an arginine-deficient diet (AD) for 20 days. Total RNA was extracted, and RT-PCR was performed as described in Materials and Methods. $\beta \mathrm{A}$ : $\beta$-actin.
IGFBP1 in liver and kidney. Figure 4 also suggests that this condition may affect the splicing of IGF1R in the kidney.

\section{Discussion}

The precise mechanisms by which gonadal steroids mediate their wide spectrum of effects remain only partially understood. In the kidney, the sexual dimorphism described in many species has been studied most extensively in mice (Bhasin et al. 2001, Kuhn 2002). Here, testosterone produces morphologic, cellular and biochemical changes, including increases in the relative renal mass and in the activities of several renal enzymes and proteins such as ornithine decarboxylase, the rate-limiting enzyme of polyamine biosynthesis (Koening et al. 1980, Berger \& Watson 1989), but the physiological significance of these changes remains unclear. Moreover, little is known about the influence of sexual renal dimorphism in arginine homeostasis, although the kidney plays an important role in the body synthesis of arginine in mammals (Barbul 1986, Boudy et al. 1993, Morris 2002). However, there is ample evidence that skeletal muscle is the major extragenital site of androgen action and that the increase in muscle mass elicited by testosterone in animals and humans can be related to the direct, indirect, priming and antiglucocorticoid action of androgens on muscle protein metabolism (Danhaive \& Rousseau 1986, 1988, Tincello et al. 1997, Verhoeven et al. 1999, Sheffield-Moore 2000, Sheffield-Moore \& Urban 2004).

We recently found that adult female mice had higher plasma arginine levels than males and that restriction of dietary arginine abolished sexual dimorphism in arginine metabolism (Ruzafa et al. 2003). The present results 
corroborate and extend our previous findings, since we have found that dietary arginine restriction not only affects plasma arginine concentrations but also reduced the circulating concentration of amino acids directly related to arginine metabolism such as citrulline and ornithine. Interestingly, arginine restriction was associated with a significant decrease in both body and renal weights in males, but not in females. Since the treatment did not decrease the concentration of testosterone in plasma, the effects observed in the male mice are likely to be due to some interaction between arginine and the mechanism of action of testosterone. This possibility is also supported by the finding that renal ornithine decarboxylase, a wellknown target of androgen action in the kidney (Berger \& Watson 1989), was dramatically decreased in the kidney of male mice fed the arginine-deficient diet. Additionally, the postulated dependence of the extragenital actions of androgens on dietary arginine was also confirmed by the observation that the anabolic effects produced by the treatment of female mice with pharmacologic doses of testosterone were impaired by arginine restriction. Although our study did not determine body composition, we can assume that the changes in body weight associated with testosterone were probably due to changes in muscle mass. This suggestion is also supported by the changes observed in the size of the lower leg.

However, our results also show that dietary arginine supplementation stimulates renal ornithine decarboxylase and kidney hypertrophy in male, but not in female, mice, having a small effect on body weight gain. These findings reveal that while dietary arginine restriction affects the action of testosterone on both muscle and kidney, the effects of arginine supplementation are mainly exerted in the kidney of male mice, suggesting that changes in the concentration of arginine in plasma might be especially relevant to the physiology of the male kidney.

While the studies carried out with intact mice indicate that the manipulation of the arginine content of the diet clearly affects arginine homeostasis and testosterone action, the experiments performed with nephrectomized mice also reveal that the anabolic action of testosterone at the muscular level can be impaired when the endogenous supply of arginine from the kidneys might be compromised as a consequence of the reduction in the renal mass. Our results also show that the refractoriness of muscle mass to testosterone is transitory and limited to the period in which, presumably, the compensatory mechanisms in the remnant kidney, or in peripheral tissues intended to normalize plasma arginine (Boudy et al. 1993), are not fully developed.

The molecular mechanisms by which arginine may influence the effects of testosterone on kidney and skeletal mass await to be determined. In fact, the precise mechanisms by which androgens induce renotrophic effects and skeletal muscle growth remain unclear, mainly because of the difficulty of isolating their effect from that of the other hormones and growth factors. Since it is known that IGFs and IGFBPs are important regulators of testosterone action on skeletal muscle mass (Urban et al. 1995, Björntorp 1996, Kuhn 2002, Sheffield-Moore \& Urban 2004), that arginine may act as a secretagogue of growth hormone $(\mathrm{GH})$ and insulin in humans and other mammals (Rosenfeld et al. 1994, Morimoto et al. 2001), that GH and IGF1 can enhance testosterone action in kidney (Niermann 1999), skeletal muscle (Urban et al. 1995) and other tissues (Björntorp 1996), and that the induction of IGFBP1 mRNA and protein is promoted by partial arginine depletion in a range similar to that found in the blood of our arginine-deficient mice (Jousse et al. 1998), it is tempting to speculate that arginine might modulate androgen action through a plausible influence on IGFs/ IGFBs. Our results showing that arginine deficiency alters the expression of IGF1, IGFBP1 and IGF1R in the kidney and IGFBP1 in the liver support this possibility.

Independently of the mechanisms involved in the interaction between arginine and testosterone, our results reveal, for the first time, that the changes in the concentration of arginine in plasma can affect the action of testosterone in muscle and kidney, and that the extent of these effects depends on the circulating levels of the hormone. The present study may have relevance to pathologic conditions associated with decrease in plasma arginine concentration, such as severe burn injury or diabetes ( $\mathrm{Yu}$ et al. 1995, 2001, Pieper \& Dondlinger 1997), or to nutritional strategies based on dietary arginine supplementation (Berad et al. 2000, Efron \& Barbul 2000, Field et al. 2000, Preiser et al. 2001, Appleton 2002, Obled et al. 2002). Specially, our results suggest that dietary arginine or L-citrulline supplementation may improve the pharmacologic action of synthetic analogs of testosterone used in clinical therapy.

\section{Acknowledgement}

This work was supported by grants from the Séneca Foundation (PI-57/00760/FS/01), Autonomous Community of Murcia. The authors declare that there is no conflict of interest that would prejudice the impartiality of this scientific work.

\section{References}

Adjei AA, Yamauchi K, Nakasone Y, Konishi M \& Yamamoto S 1995 Arginine supplemented diets inhibit endotoxin induced bacterial translocation in mice. Nutrition 11 371-374.

Appleton J 2002 Arginine: clinical potential of a semi-essential amino acid. Alternative Medicine Review 7 512-522.

Barbul A 1986 Arginine: biochemistry, physiology and therapeutic implications. Journal of Parenteral and Enteral Nutrition 10 227-238.

Bardin CW \& Catterall JF 1981 Testosterone: a major determinant of extragenital sexual dimorphism. Science 211 1285-1294. 
Berard MP, Zazzo JF, Condat P, Vasson MP \& Cynober L 2000 Total parenteral nutrition enriched with arginine and glutamate generates glutamine and limits protein catabolism in surgical patients hospitalized in intensive care units. Critical Care $\mathbf{2 8}$ 3637-3644.

Berger FG \& Watson G 1989 Androgen-regulated gene expression. Annual Reviews of Physiology 51 51-65.

Bhasin S, Woodhouse L \& Store TW 2001 Proof of the effect of testosterone on skeletal muscle. Journal of Endocrinology 170 27-38.

Björntorp P 1996 Growth hormone, insulin growth factor I and lipid metabolism: interactions with sex steroids. Hormone Research $\mathbf{4 6}$ 188-191.

Boger RH \& Bode-Boger SM 2001 The clinical pharmacology of L-arginine. Annual Review of Pharmacology and Toxicology 41 79-99.

Boudy N, Hassler C, Parvy P \& Bankir L 1993 Renal synthesis of arginine in chronic renal failure: in vivo and in vitro studies in rats with 5/6 nephrectomy. Kidney International 44 676-683.

Brinkman AO, Blok LJ, de Ruiter PE, Doesberg P, Steketee K, Berrevoets CA \& Trapman J 1999 Mechanisms of androgen receptor activation and function. Journal of Steroid Biochemistry and Molecular Biology 69 307-313.

Castillo L, Ajami A, Branch S, Chapman TE, Yu YM, Burke JF \& Young VR 1994 Plasma arginine kinetics in adult man: response to an arginine-free diet. Metabolism 43 114-122.

Cui XL, Iwasa M, Iwasa Y, Ohmori Y, Yamamoto A, Maeda H, Kume M, Ogoshi S, Yokoyama A, Sugawara T \& Funada T 1999 Effects of dietary arginine supplementation 16 on protein turnover and tissue protein synthesis in scald-burn rats. Nutrition 15 563-569.

Cynober L, Le Boucher J \& Vasson MP 1995 Arginine metabolism in mammals. Journal of Nutritional Biochemistry 6 402-413.

Danhaive PA \& Rousseau GG 1986 Binding of glucocorticoid antagonist to androgen and glucocorticoid hormone receptors in rat skeletal muscle. Journal of Steroid Biochemistry 24 481-487.

Danhaive PA \& Rousseau GG 1988 Evidence for sex-dependent anabolic response to androgenic steroids mediated by muscle glucocorticoid receptors in the rat. Journal of Steroid Biochemistry 29 575-581.

Dhanakoti SN, Brosnan JT, Herzberg GR \& Brosnan ME 1990 Renal arginine synthesis: studies in vitro and in vivo. American Journal of Physiology (Endocrinology and Metabolism) 259 E437-E442.

Efron D \& Barbul A 2000 Role of arginine in immunonutrition. Journal of Gastroenterology 35 (Suppl 12) 1220.

Fafournoux P, Bruhat A \& Jousse C 2000 Amino acid regulation of gene expression. Biochemical Journal 351 1-12.

Field CJ, Johnson I \& Pratt VC 2000 Glutamine and arginine: immunonutrients for improved health. Medical Science in Sports and Exercise 32 S377-S388.

Gayan-Ramirez G, Rollier H, Vanderhoydonc F, Verhoeven G, Gosselink R \& Decramer M 2000 Nandrolone decanoate does not enhance training effects but increases IGF-1 mRNA in rat diaphragm. Journal of Applied Physiology 88 26-34.

Gross KL, Hartman WJ, Ronnenberg A \& Prior RL 1991 Arginine-deficient diets alter plasma and tissues amino acids in young and aged rats. Journal of Nutrition 121 1591-1599.

Hannan CJ, Friedl KE, Zold A, Kettler TM \& Plymate SR 1991 Psychological and serum homovanillic acid changes in men administered androgenic steroids. Psychoneuroendocrinology 16 335-343.

Hobbs CJ, Plymate SR, Rosen CJ \& Adler RA 1993 Testosterone administration increases insulin-like growth factor-I levels in normal men. Journal of Clinical Endocrinology and Metabolism 77 776-779.

Jansson JO, Eden S \& Isakasson O 1985 Sexual dimorphism in the control of growth hormone secretion. Endocrine Reviews 6 128-150.

Jousse C, Bruhat A, Ferrara M \& Fafournoux P 1998 Physiological concentration of amino acids regulates insulin-like-growthfactor-binding protein 1 expression. Biochemical Journal 334 147-153.
Kadi F, Bonnerud P, Eriksson A \& Thornell LE 2000 The expression of androgen receptors in human neck and limb muscle: effects of training and self-administration of androgenic-anabolic steroids. Histochemistry and Cellular Biology 113 25-29.

Kitiyakara C, Chabrashvili T, Jose P, Welch WJ \& Wilcox CS 2001 Effects of dietary salt intake on plasma arginine. American Journal of Physiology (Integrative and Comparative Physiology) 280 R1069-R1075.

Koenig H, Goldstone A, Blume G \& Lu CY 1980 Testosterone mediated sexual dimorphism of mitochondria and lysosomes in mouse kidney proximal tubules. Science 209 1023-1027.

Kuhn CM 2002 Anabolic steroids. Recent Progress in Hormone Research 57 411-434.

Morimoto S, Fernández-Mejía C, Romero-Navarro G, Morales-Peza N \& Díaz-Sánchez V 2001 Testosterone effect on insulin content, messenger ribonucleic acid levels, promoter activity and secretion in the rat. Endocrinology 142 1442-1447.

Morris SM Jr 1992 Regulation of enzymes of urea and arginine synthesis. Annual Review of Nutrition 12 81-101.

Morris SM Jr 2002 Regulation of enzymes of the urea cycle and arginine metabolism. Annual Review of Nutrition 22 87-105.

Niermann GL \& Watson GL 1999 Growth hormone and insulin-like growth factor-I enhance beta-glucuronidase gene activation by androgen in mouse kidney. Molecular and Cellular Endocrinology 153 $47-55$.

Obled C, Papet I \& Breuille D 2002 Metabolic bases of amino acid requirements in acute diseases. Current Opinion in Clinical Nutrition and Metabolic Care 5 189-197.

Pieper GM \& Dondlinger LA 1997 Plasma and vascular tissue arginine are decreased in diabetes: acute arginine supplementation restores endothelium-dependent relaxation by augmenting cGMP production. Journal of Pharmacology and Experimental Therapeutics 283 684-691.

Preiser JC, Berre PJ, Van Gossum A, Cynober L, Vray B, Carpentier Y \& Vincent JL 2001 Metabolic effects of arginine addition to the enteral feeding of critically ill patients. Journal of Parenteral and Enteral Nutrition 25 182-187.

Reyes AA, Karl IE \& Klahr S 1994 Role of arginine in health and renal disease. American Journal of Physiology (Renal Physiology) 267 F331-F346.

Rose WC, Haines WJ \& Warner DT 1954 The amino acid requirements of man: the role of lysine, arginine and trypthophan. Journal of Biological Chemistry 206 421-430.

Rosenfeld RG, Rosenbloom AL \& Guevara-Aguirre J 1994 Growth hormone $(\mathrm{GH})$ insensitivity due to primary $\mathrm{GH}$ receptor deficiency. Endocrine Reviews 15 369-390.

Russell DH \& Snyder SH 1969 Amine synthesis in regenerating rat liver: extremely rapid turnover of ornithine decarboxylase. Molecular Pharmacology 5 253-262.

Ruzafa C, Monserrat F, Cremades A \& Peñafiel R 2003 Sexual dimorphism of arginine metabolism in mice: influence of dietary arginine. Journal of Nutritional Biochemistry 14 333-341.

Sheffield-Moore M 2000 Androgens and the control of skeletal muscle protein synthesis. Annals of Medicine 32 181-186.

Sheffield-Moore M \& Urban RJ 2004 An overview of the endocrinology of skeletal muscle. Trends in Endocrinology and Metabolism 15 110-115.

Shi HP, Efron DT, Most D, Tantry US \& Barbul A 2000 Supplemental dietary arginine enhances wound healing in normal but not inducible nitric oxide synthase knockout mice. Surgery 128 374-378.

Tincello DG, Saundres PTK, Hodgins MB, Simpson NB, Edwards CRW, Hargreave TB \& Wu FCW 1997 Correlation of clinical, endocrine and molecular abnormalities with in vivo responses to high-dose testosterone in patients with partial androgen insensitivity syndrome. Clinical Endocrinology 46 497-506.

Urban RJ, Bodenburg YH, Gilkison C, Foxworth J, Coggan AR, Wolfe RR \& Ferrando A 1995 Testosterone administration to 
elderly men increases skeletal muscle strength and protein synthesis. American Journal of Physiology (Endocrinology and Metabolism) 269 E820-E826.

Veldhuis JD \& Iranmanesh A 1996 Physiological regulation of the human growth hormone (GH)-insulin-like-growth factor type I (IGF-1) axis: predominant impact of age, obesity, gonadal function and sleep. Sleep 19 (Suppl 10) S221-S224.

Verhoeven G \& Swinnen JV 1999 Indirect mechanisms and cascades of androgen action. Molecular and Cellular Endocrinology 151 205-212.

Visek WJ 1986 Arginine needs, physiological state and usual diets: a re-evaluation. Journal of Nutrition 116 36-46.

Wu G \& Knabe DA 1995 Arginine synthesis in enterocytes of neonatal pigs. American Journal of Physiology (Regulatory and Integrative Comparative Physiology) 269 R621-R629.

Wu G \& Meininger CJ 2002 Regulation of nitric oxide synthase by dietary factors. Annual Review of Nutrition 22 61-86.
Wu G \& Morris SM Jr 1998 Arginine metabolism: nitric oxide and beyond. Biochemical Journal 336 1-17.

Yu YM, Ryan CM, Burke JF, Tompkins RG \& Young VR 1995 Relations among arginine, citrulline, ornithine, and leucine kinetics in adult burn patients. American Journal of Clinical Nutrition 62 960-968.

Yu YM, Ryan CM, Castillo L, Lu XM, Beaumier L, Tompkins RG \& Young VR 2001 Arginine and ornithine kinetics in severely burned patients: increased rate of arginine disposal. American Journal of Physiology (Endocrinology and Metabolism) 280 E509-E517.

Received in final form 15 July 2004

Accepted 21 July 2004

Made available online as an Accepted Preprint 4 August 2004 